Research Article

\title{
Large Data Technology-Based Analysis Method of Sudden Eco-Environmental Toxic Pollution
}

\author{
Guilan He ${ }^{1}{ }^{1}$ and Junping Yao ${ }^{2}$ \\ ${ }^{1}$ School of Artificial Intelligence and Big Data, Chongqing College of Electronic Engineering, Chongqing, China \\ ${ }^{2}$ School of Electronic and Information Engineering, Chongqing Radio \& TV University, Chongqing, China \\ Correspondence should be addressed to Guilan He; heguilan83@163.com
}

Received 1 November 2019; Accepted 24 December 2019; Published 2 June 2020

Academic Editor: Jia-Bao Liu

Copyright $\odot 2020$ Guilan He and Junping Yao. This is an open access article distributed under the Creative Commons Attribution License, which permits unrestricted use, distribution, and reproduction in any medium, provided the original work is properly cited.

\begin{abstract}
Sudden environmental toxic pollution accidents occur from time to time at home and abroad, seriously affecting the safety of the ecological environment. Different environmental factors affect the use of manual inspection and analysis methods, causing inaccurate results of inspection and analysis. In view of this problem, a large data technology-based analysis of sudden ecological environmental toxic pollution is proposed. Method. The genome and proteome in different environments were analyzed, and the target organisms were strictly defined to determine the effect of the molecular toxicity of pollution factors on the ecological environment. According to the molecular toxicity, the sudden eco-environmental toxicity pollution was analyzed using large data technology. Under the action of different particle sizes, dosages, and adsorption times of activated carbon, the experiments confirmed that the results of large data technology analysis are more accurate, which have provided necessary means for the protection of the ecological environment.
\end{abstract}

\section{Introduction}

Recently, sudden environmental toxic pollution accidents have occurred in China from time to time, seriously affecting China's economic development and people's daily life [1]. The research on this issue has become a front-burner issue in the field of environmental protection in China. Sudden ecological environmental toxic pollution indicates that water quality in the water protection area is polluted instantaneously by sudden pollutant leakage, which seriously threatens the safety of water source area [2]. The main reasons for this sudden pollution include illegal discharge of conventional pollution sources, entry of urban and rural nonpoint source pollution into river ways by rain wash, oil spill, abrupt change of water quality, abrupt change of climate, and man-made poisoning [3]. Sudden pollution phenomena are mainly reflected in water pollution; its uncertainties of occurrence, development, and harm cause serious water quality safety and ecological safety problems in China; frequent environmental pollution accidents are caused by chemicals, uncertainty of emergency objects, and so on, which not only brings huge economic loss but also results in the serious damage of ecological environment [4]. The sudden ecological environmental pollution accidents have become a potential threat to China's water source safety and environmental quality [5]. In order to prevent the sudden water pollution accidents, it is particularly necessary and urgent to analyze the sudden ecological environmental toxic pollution.

With long incubation period and no fixed treatment way, sudden ecological environmental toxic pollution accidents seriously harm the ecological environment. Therefore, correct methods shall be selected to treat sudden ecological environmental toxic pollution accidents. Previous methods used to treat sudden ecological environmental toxic pollution accidents mainly included physical, chemical, and physicochemical methods. Among them, in terms of physical method, physical separation is applied to separate nonsoluble substances from water and make the discharge of petrochemical wastewater meet the national discharge 
standard; in respect of chemical method, chemical reaction is used to treat dissolved substances in sewage, so as to improve water quality; with regard to physical-chemical method, the metabolism of microorganisms is used to treat organic pollutants suspended in water [6]. Among the above three analysis methods, the chemical method will cause secondary pollution easily, the physicochemical method takes a long time for analysis without reaching the emergency treatment effect, and the physical method is relatively safe and will not cause secondary pollution to the ecological environment [7].

With the support of physical analysis method, the research made by big data technology will undoubtedly improve the efficiency of treating sudden ecological environmental toxic pollution, so it is of great significance to promote the future development of pollution treatment plants [8].

\section{Target Organism Definition of Environmental Genome and Proteome}

As an integrated product of proteome and environmental science genome, ecological environmental proteome mainly studies the biomolecular toxicity caused by environmental pollution factors; the interaction law among pollutants, proteome, and genome; and the pollution analysis methods.

2.1. Genome. As a general term for a living entity's genes, genome is an important tool to carry information with the characteristics of uniqueness and stability. Environmental genome refers to the sum of genes responding to environmental factors, which is gradually formed with the research progress of genes responding to environmental factors. The effect of pollution factors on genes is detected to explain the molecular genetic toxicity mechanism of sudden ecological environmental toxic pollutants and the interference principle that different living entities bear different pollution factors, predict the consequences caused by pollution, and provide targeted solutions [9].

Environmental genome and proteome depend on each other [10]. The theory of environmental genome is mastered to research all cells in a living entity, and the same set of characteristic genomes is used to study the genomic gene under different pollution factors, different time conditions, and different intensity processes [11], so as to understand proteins with different polymorphism and pleiotropy. In the process of researching environmental genome, it is necessary to strictly define the target organisms and external environmental factors [12].

2.2. Proteome. Proteome is a general term of all proteins expressed by genome [13]. Protein identification technology is applied on a large scale to study the structure of genomic proteins and construct functional patterns. Currently, proteome is mainly used to study dynamic proteome with high activity, large-scale protein separation, and identification [14]. In a complex environment, the dynamic process of proteome is analyzed to provide direct evidence for the study of molecular toxicity of pollutants [15]. The invasion of exogenous pollutants threatens the living entity, directly acts on the body protein, changes the normal functions of protein, and affects the output and activity of genetic protein [16].

Environmental proteome is used to study the interaction between proteome and environmental pollution, find the markers of protein molecules of pollutant targets by applying the proteome theory, so as to analyze the effect of environmental pollution on the expression features of protein, determine the molecular toxicity caused by the action of sudden environmental toxic pollution factors on proteome, and avoid the threat to human health through the definition of target organism and external environment factors [17].

\section{Analysis of Sudden Ecological Environmental Pollution Situation}

The molecular toxicity of sudden environmental pollution was analyzed based on the above-determined proteome and genomic target organisms [18]. The molecular toxicity of pollution is shown in Figure 1.

The average value and relative pollution intensity of the polluted ecological environment were calculated according to the molecular toxicity compound [19]. The specific calculation formula is shown as follows:

$$
\begin{aligned}
& Z=\frac{X_{1}+X_{2}+X_{3}+\cdots+X_{n}}{2}, \\
& P=\frac{Z_{1}}{Z_{2}} \times 100 \% .
\end{aligned}
$$

In (1) and (2), $X$ expresses the polluted area; $Z_{1}$ represents the analysis value of relative pollution intensity under the research content of proteome; and $Z_{2}$ represents the analysis value of relative pollution intensity under the research content of proteome.

Changing situation of target organisms in the polluted ecological environment is shown in Figure 2.

According to different isoelectric points of proteins, the sample proteins were focused under the $\mathrm{PH}$ density gradient, and the proteins with different isoelectric points were obtained by the first electrophoretic separation. For the products after first electrophoretic separation [20], twodimensional gel electrophoresis was used to obtain proteins with different molecular toxicity. After ionizing the protein sample, the molecular structure was determined according to the difference in the mass-to-charge ratio of different ions [21]. Environmental proteomics was used to analyze environmental internal-secretion interfering-substance and various diseases of the reproductive system, including spermoblasts, quality of male organisms, and disproportionality between male and female organisms. Big data technology with high throughput and high sensitivity was used to analyze the corresponding location of specific proteins and determine the molecular structure of specific proteins accordingly, so as to analyze the molecular toxicity of sudden ecological environmental pollution. 


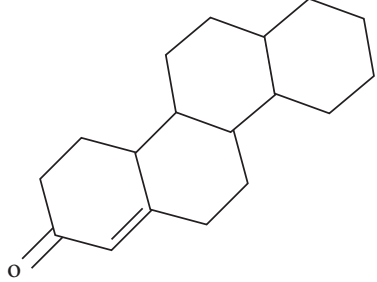

FIgURE 1: Molecular toxicity compound of pollution.

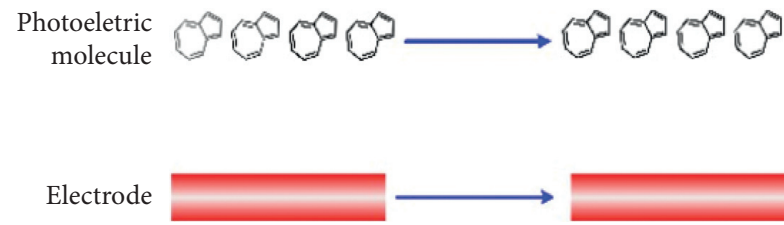

FIGURE 2: Changing situation of target organisms in the polluted ecological environment.

\section{Large Data Technology-Based Analysis of Sudden Ecological Environmental Toxic Pollution}

With strong decision-making ability and insight, big data technology is used to collect data within a certain time range by conventional software. The features of big data can be described by volume, variety, value, and speed. With large data size, volume is usually represented by $\mathrm{P}$; data are widely diverse; value refers to relatively low data value density; and speed means quick big data processing, which is a distinguishing feature used to distinguish big data technology from traditional technology. Used to better dig and store relevant governance data, big data technology is of great significance to break through the sudden ecological environmental toxic pollution in China when combined with physical methods [22].

With good adsorption effect, fruit-peel activated carbon is suitable for the analysis of sudden ecological environmental toxic pollution. Therefore, fruit-peel activated carbon was used to treat the ecological environmental pollution. Main activities of fruit-peel activated carbon are shown in Table 1.

In order to prevent activated carbon from being interfered by other impurities, the activated carbon shall be soaked in ultrapure water to remove the impurities attached to the activated carbon, dried at the temperature of $120^{\circ} \mathrm{C}$, and aired for standby application.

4.1. Particle Size of Activated Carbon. The volume and speed characteristics of big data technology were used to determine the optimal particle size of activated carbon. After adding the activated carbon of $2 \mathrm{~g}, 4 \mathrm{~g}, 6 \mathrm{~g}, 8 \mathrm{~g}$, and $10 \mathrm{~g}$ with intermediate particle size to a solution of $200 \mathrm{~mL}$, the basic water sample, the solution was stirred in the blender at a temperature of $30^{\circ} \mathrm{C}$ and speed of $150 \mathrm{r} / \mathrm{min}$, so as to investigate the probability of removing sudden ecological environmental toxic pollution by activated carbon with different particle sizes. The results of investigation are shown in Figure 3.
TABLE 1: Main activities of fruit-peel activated carbon.

\begin{tabular}{lc}
\hline Parameter & Indicator \\
\hline Weight of iodine & $1000(\mathrm{mg} / \mathrm{g})$ \\
Adsorption rate of methylene blue & $12.0(\mathrm{mg} / \mathrm{L})$ \\
Superficial area & $400-800\left(\mathrm{~m}^{2} / \mathrm{g}\right)$ \\
Density & $1.5(\mathrm{~g} / \mathrm{mL})$ \\
Particle size & $0.65-4.35 \mathrm{~nm}$ \\
Moisture & $15 \%$ \\
$\mathrm{pH}$ & $5-6$ \\
\hline
\end{tabular}

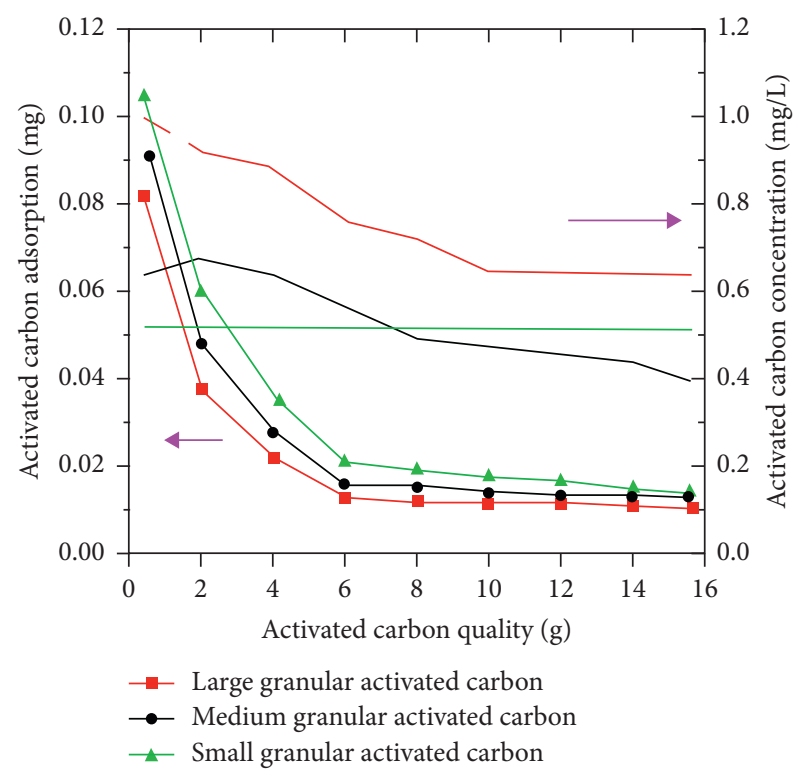

Figure 3: Adsorption capacity of activated carbon with different particle sizes.

Figure 3 shows that low-mass activated carbon has large capacity to absorb molecular toxicity of sudden ecological environmental pollution, and its adsorption capacity is increasingly gentle as the mass increases. Activated carbon with large particle size has relatively high rate of removing molecular toxicity of sudden ecological environmental pollution and relatively stable removal effect, which laid a foundation for the emergency treatment of molecular toxicity of sudden ecological environmental pollution.

4.2. Dosage of Activated Carbon. By using the speed characteristic of big data technology, the amount of activated carbon that has reached the test standard was found, and the gradient value of the dosage of activated carbon was determined. The initial reaction conditions were designed and controlled to ensure that the stirring time was $2 \mathrm{~h}$ and $24 \mathrm{~h}$, so as to fully observe the mass of activated carbon. Through analyzing the removal rate and adsorption capacity of activated carbon numerically, the gradient value of the dosage of activated carbon was determined.

From Figure 4, the dosage of activated carbon with different masses has an obvious effect on the treatment of 


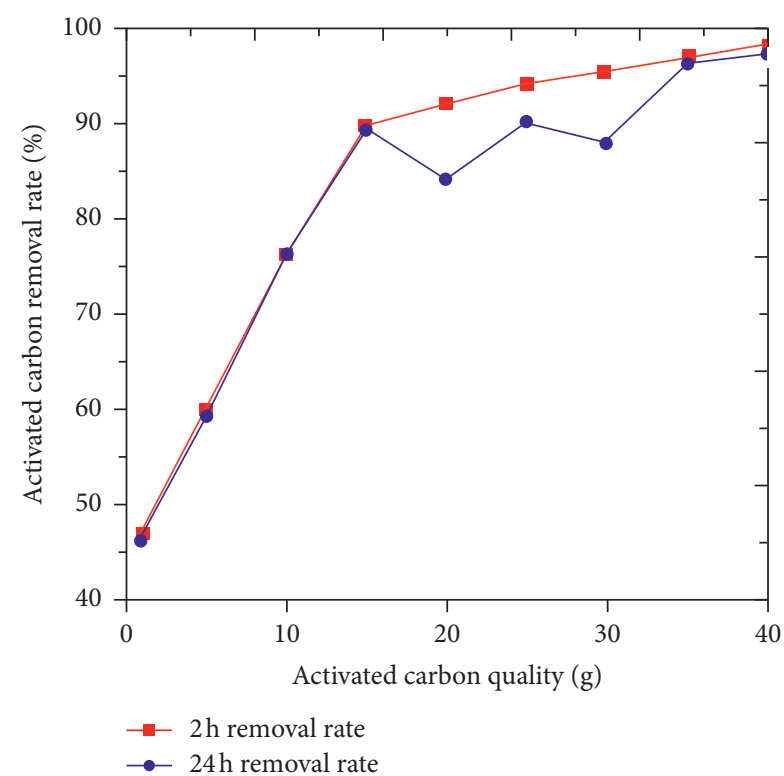

FIGURE 4: Removal rate of pollutant toxicity of activated carbon with different masses.

sudden ecological environmental toxic pollution. With the increase of the dosage of activated carbon, the removal rate rose rapidly at first and then tended to rise gently:

(1) For the removal rate of $24 \mathrm{~h}$, when the mass of activated carbon was 5,10 , and $15 \mathrm{~g}$, the removal rate of activated carbon was $60 \%, 76 \%$, and $91 \%$, respectively. When the mass of activated carbon was 20,25 , 30,35 , and $40 \mathrm{~g}$, the removal rate of activated carbon was $86 \%, 89 \%, 84 \%, 96 \%$, and $97 \%$, respectively.

(2) For the removal rate of $2 \mathrm{~h}$, when the mass of activated carbon was 5,10 , and $15 \mathrm{~g}$, the removal rate of activated carbon was $60 \%, 76 \%$, and $91 \%$, respectively. When the mass of activated carbon was 20,25 , 30,35 , and $40 \mathrm{~g}$, the removal rate of activated carbon was $93 \%, 95 \%, 96 \%, 97 \%$, and $98 \%$, respectively.

Activated carbon which has adsorbed in water sample for $2 \mathrm{~h}$ and $24 \mathrm{~h}$ has basically the same removal efficiency. Because activated carbon almost reached the saturated state after having adsorbed for $2 \mathrm{~h}$, adsorption time shall be less than or equal to $2 \mathrm{~h}$; in this way, the gradient value of activated carbon dosage was determined, and the level of sudden ecological environmental toxic pollution was analyzed based on the dosage of activated carbon at $2 \mathrm{~h}$.

4.3. Adsorption Time of Activated Carbon. Selected by using the volume characteristic of big data technology, the adsorption time of activated carbon shall be more than $10 \mathrm{~min}$, and too short adsorption time of activated carbon put repeatedly and manually shall be avoided. In order to avoid serious pollution caused by excessive flow velocity, the adsorption time of activated carbon shall not be too long; besides, because activated carbon almost reaches the saturation state after $2 \mathrm{~h}$, the minimum adsorption time of activated carbon shall be set as $10 \mathrm{~min}$, so as to investigate the probability of removing sudden ecological environmental toxic pollution by activated carbon at different adsorption time. The research results are shown in Figure 5.

Figure 5 shows that activated carbon with different masses has obvious effect on the treatment of sudden ecological environmental toxic pollution. As time goes by, three broken lines show different states:

(1) The removal rate of activated carbon with small particle size has been $92 \%$ from $10 \mathrm{~min}$ to $70 \mathrm{~min}$ but increased to $99 \%$ from $70 \mathrm{~min}$ to $80 \mathrm{~min}$.

(2) The removal rate of activated carbon with medium particle size was $60 \%, 76 \%$, and $84 \%$, respectively, at 10,20 , and $30 \mathrm{~min}$. The broken line of the removal rate of activated carbon showed a slow rising trend at $40,50,60,70$, and $80 \mathrm{~min}$.

(3) The removal rate of activated carbon with large particle size was $52 \%$ and $69 \%$, respectively, at 10 and 20 minutes. The broken line of the removal rate of activated carbon also showed a slow rising trend at $40,50,60,70$, and $80 \mathrm{~min}$.

With the increase of adsorption time, the optimal adsorption time of activated carbon with different particle sizes was different: $70 \mathrm{~min}$ with small particle size, $30 \mathrm{~min}$ with medium particle size, and $20 \mathrm{~min}$ with large particle size. The optimal adsorption time of activated carbon with different particle sizes can be determined by using big data technology, so as to analyze the degree of sudden toxic pollution of ecological environment.

Through analyzing the adsorption time of activated carbon with different particle sizes and dosages, the big data technology was used to study the sudden ecological environmental toxic pollution. According to the research results, activated carbon with large particle size has high rate of removing molecular toxicity of sudden ecological environmental pollution, with relatively stable removal effect; at $2 \mathrm{~h}$, the activated carbon almost reached the saturated state, and the gradient value of the dosage of activated carbon was determined by taking the dosage of activated carbon dosage at $2 \mathrm{~h}$ as the standard; the activated carbon with different particle sizes has different optimal adsorption time. According to the analysis content, the optimal adsorption time of activated carbon with different particle sizes was determined to ensure the stable effect of removing molecular toxicity of sudden ecological environmental pollution.

\section{Analysis of Experimental Verification}

In order to further verify the feasibility and stability of the analysis methods of sudden ecological environmental toxic pollution based on big data technology, further experimental verification and analysis of this technology shall be made.

5.1. Experimental Environment. In the laboratory, the software and hardware environment constructed by existing experimental conditions were used to test the sudden ecological environmental toxic pollution analysis methods 


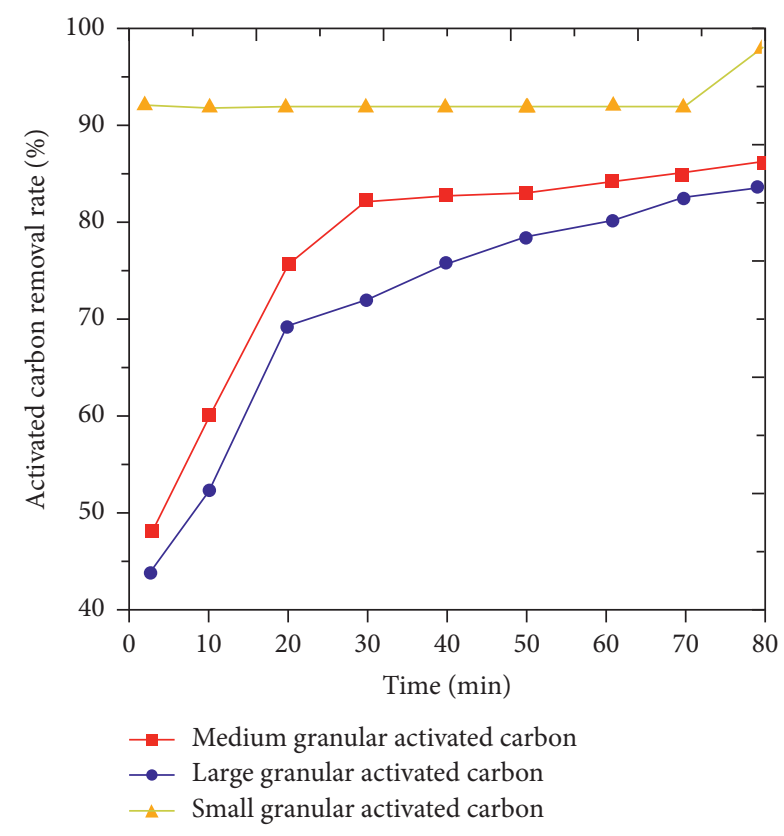

Figure 5: Removal rate of activated carbon at different time.

based on big data technology. The test equipment included 3 PC main engines, 1 communication server, and 1 database server. The specific configuration parameters are shown in Table 2.

The list of software version numbers is shown in Table 3.

The database was deployed on the database server, and the related programs were deployed on the application server.

\subsection{Analysis and Discussion of Experimental Results}

5.2.1. Changing the Particle Size of Activated Carbon. In this experiment, during the process of treating the molecular toxicity of sudden ecological environmental pollution, we only needed to change the particle size of activated carbon and divide it into large, medium, and small with the ranges of 5-8 mesh, 8-21 mesh, and >21 mesh, successively. The activated carbon with the dosage of $15 \mathrm{~g}$ and the concentration of $45 \mathrm{~g} / \mathrm{L}$ was selected to be absorbed in water for about one day, so as to obtain the water samples of the molecular toxicity of sudden ecological environmental pollution with different concentrations. The concentrations of water samples are shown in Table 4.

Based on Table 4, manual analysis method, chemical analysis method, and big data technology analysis method were used to verify and analyze the degree of molecular toxicity of sudden ecological environmental pollution.

(1) Large Particle Size. Changing situation of the toxicity of pollutants with large particle size under different analysis methods is shown in Figure 6.

From Figure 6, with the increase of time, the toxicity of pollutants changed from high toxicity of $0.32 \mathrm{mg} / \mathrm{L}$ to low toxicity of $0.22 \mathrm{mg} / \mathrm{L}$ by manual analysis method; the toxicity
TABLE 2: Table of configuration parameters.

\begin{tabular}{lcc}
\hline Hardware & Equipment & Parameter explanation \\
\hline CPU & Main engine & $\begin{array}{c}\text { Intel Pentium }(R) \text { dual- } \\
\text { core CPU E5400 }\end{array}$ \\
& $\begin{array}{c}\text { Data communication } \\
\text { server }\end{array}$ & I3-6100/8 G/1 T \\
& Database server & I3-6100/8 G/1 T \\
Internal & Main engine & $4 \mathrm{G}$ \\
storage & Data communication & $16 \mathrm{G}$ \\
& Database server & $16 \mathrm{G}$ \\
\hline \multirow{3}{*}{ Hardware } & Main engine & $500 \mathrm{G}$ \\
& Data communication & $1 \mathrm{~T}$ \\
& Database server & $1 \mathrm{~T}$
\end{tabular}

TABLE 3: List of software version numbers.

\begin{tabular}{lc}
\hline Name & Version no. \\
\hline Ubuntu & 11.05 \\
JDK & $1.6 .0 \_64$ \\
Hadoop & 1.1 .2 \\
Sqoop & 1.4 .4 \\
Hive & 0.11 .1 \\
\hline
\end{tabular}

of pollutants changed from high toxicity of $0.32 \mathrm{mg} / \mathrm{L}$ to low toxicity of $0.20 \mathrm{mg} / \mathrm{L}$ by chemical method; and the toxicity of pollutants changed from high toxicity of $0.32 \mathrm{mg} / \mathrm{L}$ to low toxicity of $0.06 \mathrm{mg} / \mathrm{L}$ by big data technology, which showed that the physical separation method in the big data technology analysis method can be used to remove a large amount of biological toxicity of pollutants with large particle size.

(2) Medium Particle Size. Changing situation of the toxicity of pollutants with medium particle size under different analysis methods is shown in Figure 7.

The toxicity of pollutants changed from high toxicity of $0.21 \mathrm{mg} / \mathrm{L}$ to medium toxicity of $0.14 \mathrm{mg} / \mathrm{L}$ by manual analysis; the toxicity of pollutants changed from high toxicity of $0.21 \mathrm{mg} / \mathrm{L}$ to low toxicity of $0.12 \mathrm{mg} / \mathrm{L}$ by chemical method; and the toxicity of pollutants changed from high toxicity of $0.32 \mathrm{mg} / \mathrm{L}$ to low toxicity of $0.02 \mathrm{mg} / \mathrm{L}$ by big data technology, which showed that the physical separation method in the big data technology analysis method can be used to remove a large amount of biological toxicity of pollutants with medium particle size.

(3) Small Particle Size. Changing situation of the toxicity of pollutants with small particle size under different analysis methods is shown in Figure 8.

The toxicity of pollutants changed from high toxicity of $0.20 \mathrm{mg} / \mathrm{L}$ to medium toxicity of $0.13 \mathrm{mg} / \mathrm{L}$ by manual analysis method; the toxicity of pollutants changed from high toxicity of $0.20 \mathrm{mg} / \mathrm{L}$ to medium toxicity of $0.10 \mathrm{mg} / \mathrm{L}$ by chemical method; and the toxicity of pollutants changed from high toxicity of $0.20 \mathrm{mg} / \mathrm{L}$ to low toxicity of $0.02 \mathrm{mg} / \mathrm{L}$ by big data technology, which showed that the physical 
TABLE 4: Samples with different particle sizes of molecular toxicity of ecological environmental pollution.

\begin{tabular}{lccc}
\hline Particle size of activated carbon & Large-sized particle & Medium-sized particle & Small-sized particle \\
\hline Effluent concentration of samples $(\mathrm{mg} / \mathrm{L})$ & 0.32 & 0.21 & 0.20 \\
Relative pollution intensity & 0.10 & 0.15 & 0.16 \\
Toxicity level & Highly toxic & Highly toxic & Highly toxic \\
\hline
\end{tabular}

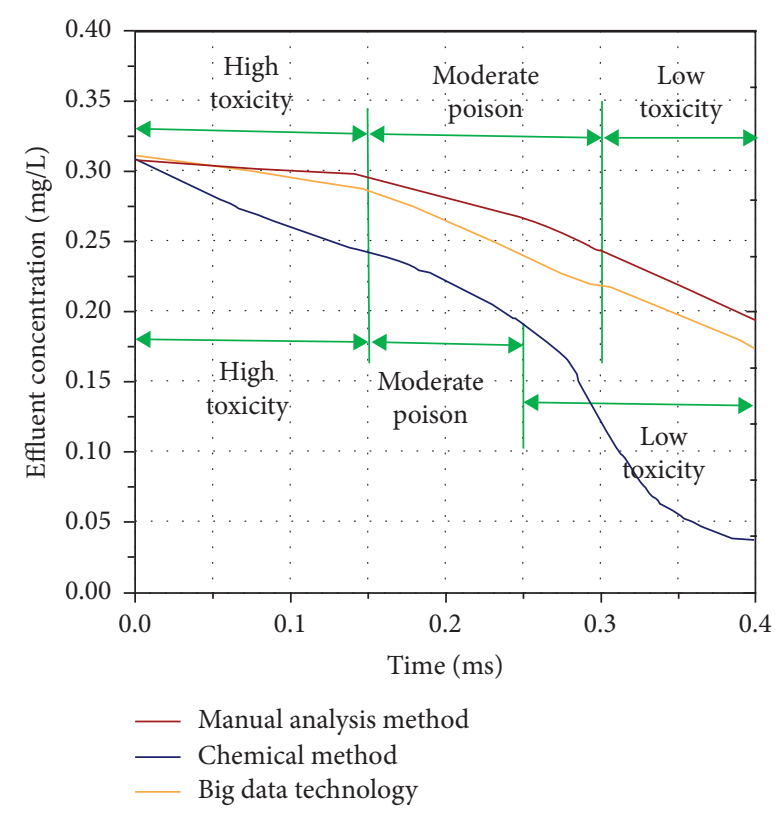

Figure 6: Changing situation of the toxicity of pollutants with large particle size under different analysis methods.

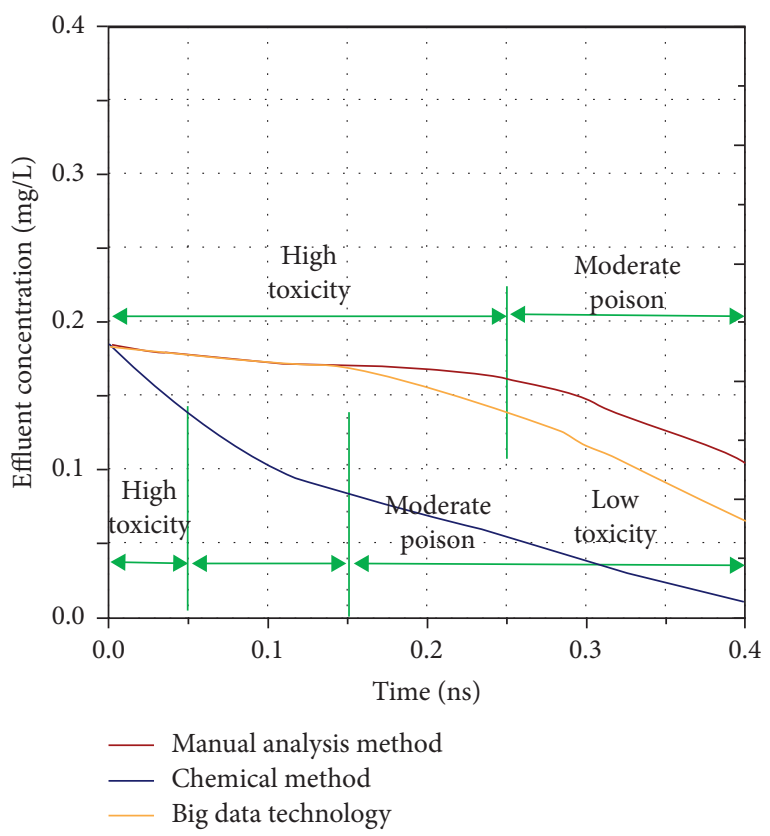

FIGURE 7: Changing situation of the toxicity of pollutants with medium particle size under different analysis methods.

separation method in the big data technology analysis method can be used to remove a large amount of biological toxicity of pollutants with small particle size.

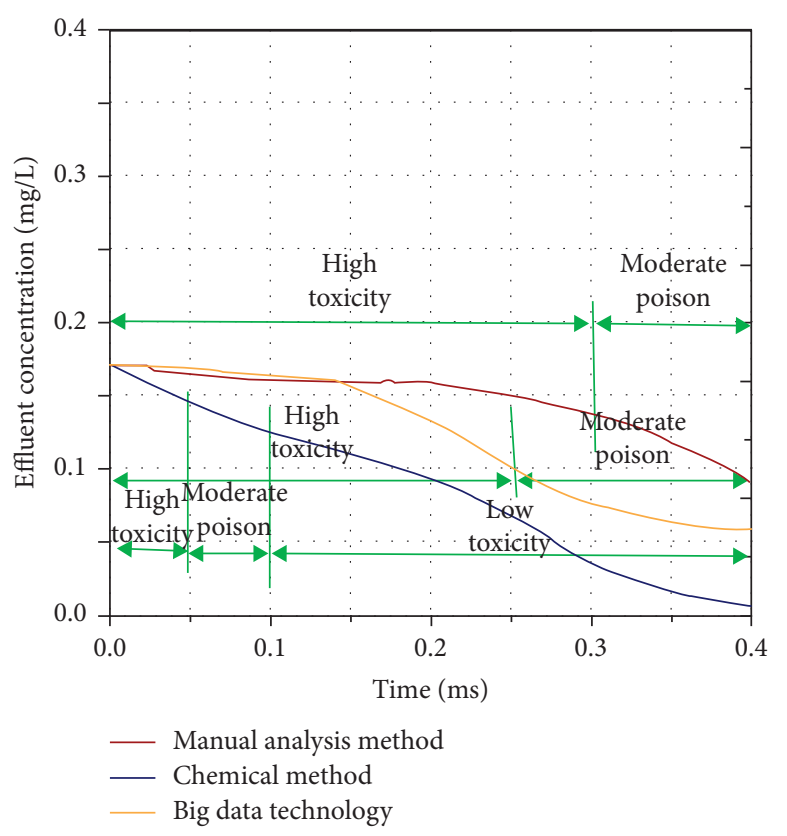

FIgURE 8: Changing situation of the toxicity of pollutants with small particle size under different analysis methods.

5.2.2. Changing the Dosage of Activated Carbon. In this experiment, during the process of treating the molecular toxicity of sudden ecological environmental pollution, we only needed to change the dosage of activated carbon and keep other conditions unchanged. The effluent concentration is shown in Table 5.

Based on Table 5, three analysis methods were used to verify and analyze the level of molecular toxicity of sudden ecological environmental pollution, which is shown in Table 6 .

From Table 6, by the manual analysis method, activated carbon with different dosages has different levels of molecular toxicity of sudden ecological environmental pollution. The activated carbon with the dosage of $2 \mathrm{~g}, 4 \mathrm{~g}, 6 \mathrm{~g}, 8 \mathrm{~g}, 20 \mathrm{~g}$, and $40 \mathrm{~g}$ was consistent with the original toxicity level; by the chemical analysis method, the activated carbon with the dosage of $2 \mathrm{~g}, 4 \mathrm{~g}$, $20 \mathrm{~g}$, and $40 \mathrm{~g}$ was consistent with the original toxicity level; by the big data analysis method, activated carbon with different dosages had different levels of molecular toxicity of sudden ecological environmental pollution and was consistent with the original toxicity level, which showed that big data analysis method can achieve more accurate analyzing results.

5.2.3. Changing the Adsorption Time of Activated Carbon. In this experiment, during the process of treating molecular toxicity of sudden ecological environmental pollution, we only needed to change the adsorption time of activated carbon. The effluent concentration is shown in Table 7. 
TABLE 5: Samples with different dosages of molecular toxicity of sudden ecological environmental pollution.

\begin{tabular}{lccc}
\hline Dosage $(\mathrm{g})$ & Concentration of activated carbon $(\mathrm{g} / \mathrm{L})$ & Relative pollution intensity & Toxicity level \\
\hline 2 & 14 & 0.25 & Highly toxic \\
4 & 28 & 0.29 & Highly toxic \\
6 & 42 & 0.33 & Heavily toxic \\
8 & 56 & 0.35 & Heavily toxic \\
10 & 70 & 0.40 & Heavily toxic \\
20 & 140 & 0.40 & Medium toxic \\
40 & 280 & 0.45 & Medium toxic \\
80 & 560 & 0.55 & Low toxic \\
100 & 700 & 0.65 & Low toxic \\
\hline
\end{tabular}

TABLE 6: Three analysis methods to verify the pollution level of molecular toxicity.

\begin{tabular}{lccc}
\hline Dosage of activated carbon $(\mathrm{g})$ & Manual analysis method & Chemical analysis method & Big data technology analysis \\
\hline 2 & Highly toxic & Highly toxic & Highly toxic \\
4 & Highly toxic & Highly toxic & Highly toxic \\
6 & Heavily toxic & Highly toxic & Heavily toxic \\
8 & Heavily toxic & Highly toxic & Heavily toxic \\
10 & Medium toxic & Medium toxic & Heavily toxic \\
20 & Medium toxic & Medium toxic & Medium toxic \\
40 & Medium toxic & Medium toxic & Medium toxic \\
80 & Medium toxic & Medium toxic & Low toxic \\
100 & Medium toxic & Medium toxic & Low toxic \\
\hline
\end{tabular}

TABle 7: Samples with different adsorption time of molecular toxicity of sudden ecological environmental pollution.

\begin{tabular}{|c|c|c|c|}
\hline $\begin{array}{l}\text { Adsorption } \\
\text { time }(\mathrm{h})\end{array}$ & $\begin{array}{c}\text { Concentration of } \\
\text { activated carbon } \\
(\mathrm{mg} / \mathrm{L})\end{array}$ & $\begin{array}{l}\text { Relative } \\
\text { pollution } \\
\text { intensity }\end{array}$ & $\begin{array}{c}\text { Toxicity } \\
\text { level }\end{array}$ \\
\hline 0 & 0.23 & 0.10 & $\begin{array}{c}\text { Acutely } \\
\text { toxic }\end{array}$ \\
\hline 0.2 & 0.21 & 0.11 & $\begin{array}{c}\text { Acutely } \\
\text { toxic }\end{array}$ \\
\hline 0.4 & 0.19 & 0.18 & $\begin{array}{l}\text { Highly } \\
\text { toxic }\end{array}$ \\
\hline 0.6 & 0.18 & 0.25 & $\begin{array}{l}\text { Highly } \\
\text { toxic }\end{array}$ \\
\hline 0.8 & 0.15 & 0.32 & $\begin{array}{c}\text { Heavily } \\
\text { toxic }\end{array}$ \\
\hline 1.0 & 0.12 & 0.11 & $\begin{array}{c}\text { Medium } \\
\text { toxic }\end{array}$ \\
\hline 1.2 & 0.9 & 0.18 & $\begin{array}{c}\text { Medium } \\
\text { toxic }\end{array}$ \\
\hline 1.4 & 0.08 & 0.22 & $\begin{array}{c}\text { Medium } \\
\text { toxic }\end{array}$ \\
\hline 1.6 & 0.04 & 0.25 & $\begin{array}{c}\text { Medium } \\
\text { toxic }\end{array}$ \\
\hline 1.8 & 0.02 & 0.24 & $\begin{array}{c}\text { Medium } \\
\text { toxic }\end{array}$ \\
\hline
\end{tabular}

Based on Table 7, three analysis methods were used to verify and analyze the level of molecular toxicity of sudden ecological environmental pollution, which is shown in Figure 9.

From Figure 9, with the increase of adsorption time, by big data technology, activated carbon was consistent with the actual concentration; however, the concentrations obtained by manual analysis method and chemical method were greatly different from the actual concentration.

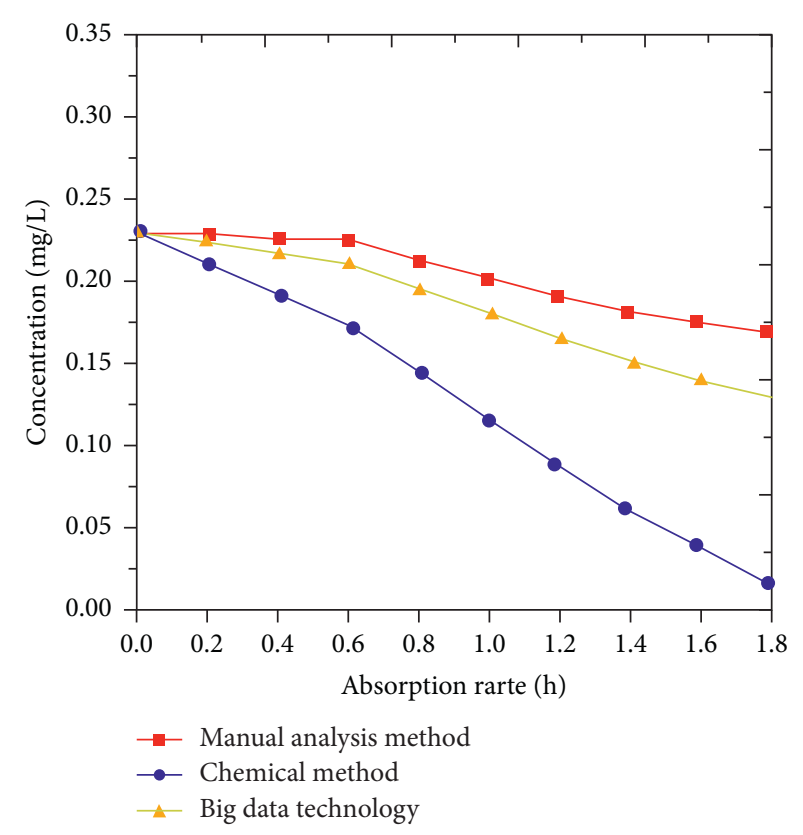

FIGURE 9: Different analysis methods to verify the pollution level of molecular toxicity.

In conclusion, the analysis results of sudden ecological environmental toxic pollution by using the combination of big data technology with physical methods were accurate and consistent with the actual results.

\section{Conclusion}

Starting from the subjects of environmental proteome and genome, the research on the molecular toxicity of sudden 
ecological environmental pollution is applicable to the analysis techniques of environment with different pollution levels. Taking the database of environmental proteome as the center, the molecular toxicity was detected and analyzed by big data technology. During the process of analyzing the molecular toxicity of sudden ecological environmental pollution, big data technology can be used to successfully analyze the damage situation of molecular genome as a simple tool to supervise and assess molecular toxicity, which is expected to be applied in the field of environmental pollutant toxicity detection.

Due to the restrictions on experimental environment, the big data technology involved in the research content is only supported by relevant theories and simple equipment. This means that the content of the article is more theoretical. In terms of detecting the existing pollution molecules, the research on the molecular toxicity of sudden ecological environmental pollution plays a certain guiding role in protecting the environment, but there are still some limitations. Therefore, in the follow-up research process, it is necessary to combine practice with experiment, improve the experimental conditions, and increase the treatment efficiency of pollution molecules.

\section{Data Availability}

No data were used to support this study.

\section{Conflicts of Interest}

The authors declare that they have no conflicts of interest.

\section{References}

[1] A. M. Wu, X. L. Zhao, Y. Feng et al., "The enlightenment of American ecotoxicology database to Chinese database construction," Environmental Science Research, vol. 30, no. 4, pp. 636-644, 2017.

[2] Z. Wang, "Research hotspot and frontal analysis of mine ecological environmental restoration-big data visualization research based on vosviewer and citespace," Geological Bulletin of China, vol. 37, no. 12, pp. 2144-2153, 2018.

[3] M. M. Zhao, S. C. Zhao, and L. Y. Zhao, "Application progress and prospect of big data in the field of ecological environment," Journal of Applied Ecology, vol. 28, no. 5, pp. 17271734, 2017.

[4] W. Tang, Q. Yang, C. Huang et al., "Research on the change features of automobile pollutant emission in hangzhou based on big data analysis and IVE model," Journal of Environmental Sciences, vol. 38, no. 1, pp. 71-78, 2018.

[5] Y. Li, J. Yang, and J. Du, "Prospect of medical disruptive technologies," Chinese Journal of Engineering Science, vol. 20, no. 6, pp. 64-56, 2018.

[6] Y. Xia, Q. Yang, C. Xu et al., "Research on high-resolution ammonia emission inventory from agricultural sources in hangzhou based on big data analysis," Journal of Environmental Sciences, vol. 38, no. 2, pp. 661-668, 2018.

[7] W. Liu, J. Yang, H. Gui, P. Xie, R. Liu, and J. Wei, "Study on the development of multi perception system for "internet plus" smart environmental protection," Chinese Journal of Engineering Science, vol. 20, no. 2, pp. 111-119, 2018.
[8] Q. Q. Chen and S. Y. Yang, "Aquatic ecotoxicity and carrier function of microplastics pollution," Asian Journal of Ecotoxicology, vol. 19, no. 1, pp. 16-30, 2018.

[9] Y. W. Wang, Y. Wang, and G. B. Jiang, "Analysis method, pollution status and toxicity effect of short-chain chlorinated paraffin," Progress in Chemistry, vol. 32, no. 9, pp. 919-929, 2017.

[10] Q. Q. Zhang, M. Qiao, and H. F. Chi, "Review of test methods for soil ecotoxicity," Asian Journal of Ecotoxicology, vol. 12, no. 4, pp. 76-97, 2017.

[11] Q. L. Bao, W. H. Li, Y. Z. Huang et al., "Ecotoxicity of soil Cd pollution to springtail folsomia candida," Asian Journal of Ecotoxicology, vol. 12, no. 2, pp. 169-176, 2017.

[12] Z. C. Ma, "Preliminary application of mix index in the research on combined toxicity of environmental mixtures," Asian Journal of Ecotoxicology, vol. 16, no. 3, pp. 62-71, 2017.

[13] L. P. Guo, T. T. Liu, H. R. Li et al., "Change characteristics of environmental meteorological conditions of "sudden" severe air pollution in langfang," Environmental Pollution and Prevention, vol. 22, no. 4, p. 120, 2017.

[14] H. Li, "Research progress on environmental exposure, environmental behavior and toxic effects of organophosphate fire retardants," Environmental Engineering, vol. 36, no. 9, pp. 185-189, 2018.

[15] Z. Q. Zhang, "Analysis of bacteriostatic activity, cytotoxicity and safety of acetone extracts from five medicinal plants," Molecular Plant Breeding, vol. 16, no. 23, pp. 7849-7855, 2018.

[16] M. M. Wang, "Screening of watershed priority pollutant based on environmental risk ranking," Environmental Science, vol. 39, no. 10, pp. 82-88, 2018.

[17] Y. Luo, B. Q. Zhang, X. Q. Ren et al., "Pollution status and toxicity research progress of CL-pahs," Asian Journal of Ecotoxicology, vol. 12, no. 3, pp. 120-134, 2017.

[18] Y. D. Zou, Q. Q. Xu, G. Zhang et al., "Research progress on the joint toxic effects of microplastics and pesticide pollution," Asian Journal of Ecotoxicology, vol. 12, no. 4, pp. 25-33, 2017.

[19] Y. Z. Pan, H. Y. Sun, D. L. Wang, Z. F. Lin, C. S. Yin, and $\mathrm{X}$. D. Wu, "Research progress on the inter-related phenomenon between the model curve of joint toxicity evaluation of mixed pollutants and the actual concentration effect curve," Asian Journal of Ecotoxicology, vol. 32, no. 3, pp. 72-85, 2017.

[20] N. N. Lu, W. C. Song, M. Q. Wang, S. H. Sun, and R. B. Jia, "Research on the behavioral toxicity of acute exposure of malathion to zebrafish," Asian Journal of Ecotoxicology, vol. 12, no. 4, pp. 249-254, 2017.

[21] M. Y. Wang, "Pollution and ecological toxicity of antidepressants in water environment," Journal of Chemical Engineering of Chinese University, vol. 30, no. 5, pp. 1009-1027, 2017.

[22] J.-B. Liu, J. Zhao, H. He, and Z. Shao, "Valency-based topological descriptors and structural property of the generalized sierpiński networks," Journal of Statistical Physics, vol. 177, no. 6, pp. 1131-1147, 2019. 